\title{
Efek Urine Sapi terhadap Keberhasilan Cangkok Salak
}

\section{The Effect of Cow Urine on Success of Snake Fruit Layering}

\author{
Sri Hadiati',*, Tri Budiyanti', Mizu Istianto1, Melli Fitriani² \\ ${ }^{1}$ Balai Penelitian Tanaman Buah Tropika, Jl Raya Solok-Aripan km 8 Solok, Sumatera Barat 20137 Indonesia \\ ${ }^{2}$ Balai Pengkajian Teknologi Pertanian Kepulauan Riau, Jl. Pelabuhan Sungai Jang No. 38 Tanjung Pinang, Kepulauan \\ Riau, Indonesia \\ *E-mail Penulis Korespondensi: shadiati@yahoo.com
}

Tanggal submisi: 20 Februari 2020; Tanggal penerimaan: 12 Juni 2020

\begin{abstract}
Propagation of snake fruit (Salacca zalacca) plants can be done by layering with the advantage that the plant is identical to its parent, the fruiting age is earlier and the type of male or female plant can be known in advance. For the purpose of propagation, it was necessary to get the proper concentration of cow urine on snake fruit propagation by layering. This research was carried out in April-December 2017 in Bintan Regency Seed Unit, Riau Islands. The materials used for the layering were lateral shoots of Sari Intan snake fruit which had 3 to 4 leaves. This design research used was a Randomized Block Design, consist of five treatment levels of cow urine concentrations, i.e. 0 (control), 10\%, 20\%, 30\%, and 40\%, with three replication. Every treatment consisted of 5 shoots. The variables researched were leaf number, plant height, primary root number and length, root weight, percentage of successful layering, percentage of seedlings that had dry shoots. The results indicated that the number of primary roots and height of snake fruit seedlings increased by application of $20 \%$ cow urine. Thus, the use of cow urine at the right concentration of $20 \%$ in snake fruit layering could increase its success.
\end{abstract}

Keywords: cow urine, layering, plant propagation, Salacca zalacca

\begin{abstract}
ABSTRAK
Perbanyakan tanaman salak (Salacca zalacca) bisa dilakukan melalui cangkok dengan keuntungan yaitu hasil buahnya sama dengan induknya, umur berbuah lebih cepat serta jenis salak jantan atau betina dapat diketahui sebelumnya. Penelitian ini bertujuan untuk mendapatkan konsentrasi urine sapi yang tepat pada perbanyakan salak secara cangkok. Penelitian telah dilakukan pada bulan April-Desember 2017 di Balai Benih Kabupaten (BBK) Bintan, Kepulauan Riau. Bahan yang digunakan untuk cangkok yaitu tunas anakan salak Sari Intan yang berdaun 3-4 pelepah. Desain penelitian ini menggunakan Rancangan Acak Kelompok, terdiri atas lima level konsentrasi urine sapi, yakni 0 (kontrol), 10\%, 20\%, 30\%, dan 40\%, dengan pengulangan tiga kali. Setiap perlakuan terdiri atas 5 tunas anakan. Peubah yang diamati meliputi jumlah daun, tinggi tanaman, jumlah dan panjang akar primer, bobot akar, persentase benih hidup, persentase benih mengalami kekeringan pada pucuk daun. Hasil penelitian menunjukkan bahwa jumlah akar primer dan tinggi bibit salak dapat meningkat dengan pemberian urine sapi pada konsentrasi 20\%. Dengan demikian, penggunaan urine sapi dengan konsentrasi yang tepat yakni pada konsentrasi $20 \%$ pada pencangkokan salak dapat meningkatkan keberhasilannya.
\end{abstract}

Kata kunci: cangkok, perbanyakan, Salacca zalacca, urine sapi

\section{PENDAHULUAN}

Salak mempunyai nilai ekonomis serta berdaya saing tinggi, terbukti dengan permintaan di dalam dan luar negeri yang terus meningkat. Produksi salak nasional tahun 2017 sebanyak 953.845 ton dan meningkat sebesar $35,81 \%$ dibandingkan produksi tahun 2016 (Kementan, 2018). Daging buah salak yang tebal, citarasa manis, tidak sepat, serta mempunyai daya simpan yang lama sangat disukai oleh konsumen. Saat ini, jumlah varietas yang sesuai dengan keinginan konsumen tersebut sangat terbatas. Balai Penelitian Tanaman Buah (Balitbu) Tropika telah menghasilkan tiga varietas salak unggul yaitu Sari Intan 48, Sari Intan 295, dan Sari Intan 541 (Hadiati, 2016). Namun sampai saat ini ketiga varietas tersebut belum berkembang di masyarakat karena jumlah benih masih terbatas. 
Pada tanaman salak (Salacca zalacca) perbanyakan tanaman sebaiknya menggunakan cangkok. Keuntungan perbanyakan secara cangkok yaitu hasil buahnya sama dengan induknya, umur lebih genjah (berbuah umur 1-2 tahun setelah tanam di lapang), dan jenis kelamin tanaman salak dapat diketahui sebelumnya. Adapun kerugiannya yaitu perbanyakannya lebih sukar dibandingkan dengan perbanyakan generatif dan jumlah tunas yang dapat dicangkok per rumpun terbatas (Kusumo et al., 1995).

Beberapa hal yang berpengaruh terhadap tingkat keberhasilan pencangkokan antara lain yaitu ukuran tunas yang akan dicangkok, umur pohon induk, ketrampilan mencangkok. Tingkat keberhasilan cangkok pada salak umur 5-15 tahun lebih tinggi dibandingkan salak umur di atas 15 tahun (Kasijadi et al., 1999). Panen tunas yang telah dicangkok tergantung pada tumbuhnya akar pada tunas tersebut. Semakin cepat dan banyak akar tumbuh, maka tunas tersebut dapat segera dipanen/dipisahkan dari induknya. Pada umumnya cangkokan dapat dipisah dari induknya pada umur 4-6 bulan setelah cangkok (Kusumo et al., 1995).

Beberapa hasil penelitian untuk menginduksi akar pada cangkok salak telah dilakukan, antara lain dengan penyemprotan 500-3000 ppm IBA pada bonggol akar, pemakaian Rootone $\mathrm{F}$ sebanyak $50 \mathrm{mg}$ atau pemberian limbah bawang merah sebanyak $75 \mathrm{~g}$ yang ditempelkan pada bonggol akar (Sudaryono dan Soleh, 1994). Campuran tanah dan pupuk kandang dengan perbandingan 1:1 merupakan media yang terbaik untuk cangkok (Purbiati et al., 1994).

Urine sapi mengandung hormon tumbuh Indole 3-butyric acid. Zat pengatur tumbuh ini dapat digunakan untuk merangsang pertumbuhan akar dalam penyetekan maupun pencangkokan. Urine sapi dapat memacu pertumbuhan tanaman mulai dari perkembangan sel, pertumbuhan bibit, akar, tunas, batang dan bunga sampai menjadi buah (Priantyo, 2002). Penggunaan urine sapi telah banyak digunakan untuk mempercepat pertumbuhan akar pada pembibitan tanaman. Pertumbuhan setek buah naga dapat dipacu dengan pemberian urine sapi konsentrasi $50 \%$ yang ditunjukkan dengan saat muncul tunas lebih cepat, jumlah tunas, jumlah akar, panjang akar, volume akar, bobot segar dan bobot kering bibit tanaman buah naga yang lebih tinggi dibandingkan perlakuan lainnya (Yunanda et al., 2015). Pemberian urine sapi $20 \%$ pada setek lada dapat meningkatkan persentase setek hidup dan berakar, panjang akar, jumlah akar dan tunas (Riski et al., 2016). Urine sapi pada umumnya digunakan sebagai pupuk organik cair dengan kandungan antara lain auksin, 1,20\% Nitrogen, 0,5\% Pospor, 1,50\% Kalium, 25,5 $\mathrm{mg} / \mathrm{L}$ Calsium dan $0,706 \%$ C-organik, sehingga berpengaruh terhadap perkembangan sel dan pembentukan kalus (Putri et al., 2016). Berdasarkan hasil kajian tersebut di atas, maka penelitian ini bertujuan untuk memperoleh konsentrasi urine sapi yang tepat pada perbanyakan salak secara cangkok.

\section{METODE PENELITIAN}

\section{Waktu dan Tempat}

Penelitian dilakukan mulai bulan AprilDesember 2017 di Balai Benih Kabupaten (BBK) Bintan, Kepulauan Riau.

\section{Bahan dan Alat}

Bahan yang dipakai untuk cangkok yaitu tunas anakan salak Sari Intan yang berdaun 3-4 pelepah, urine sapi, pupuk NPK, polibag, dan botol plastik. Alat yang digunakan antara lain pisau, meteran, dodos, gunting pangkas, dan alat budidaya lainnya.

\section{Prosedur Penelitian}

Desain yang dipakai pada penelitian ini yaitu Rancangan Acak Kelompok, tersusun atas lima level konsentrasi urine sapi $(0,10 \%, 20 \%, 30 \%$, dan $40 \%)$ dengan tiga kali pengulangan. Masing-masing unit perlakuan sebanyak lima tunas anakan. Perlakuan urine sapi yang dipergunakan adalah dalam bentuk pupuk cair berbahan dasar urine sapi yang telah difermentasi dengan kandungan unsur hara yaitu $0,51 \%$ C-organik, $0,04 \% \mathrm{~N}$-total, $12,75 \% \mathrm{C} / \mathrm{N}$ ratio, $\mathrm{pH}\left(\mathrm{H}_{2} \mathrm{O}\right) \mathrm{8,65}$, $0,09 \% \quad \mathrm{P}_{2} \mathrm{O}_{5}$ total, $0,06 \% \mathrm{~S}, 130,00 \mathrm{ppm}$ Fe-Total, $1,45 \% \mathrm{~K}_{2} \mathrm{O}, 11,00 \mathrm{ppm} \mathrm{Pb}, 1,00 \mathrm{ppm} \mathrm{Cd}$, dan 25,20 ppm Mn (Fitriani dan Salfina, 2016).

Kegiatan pencangkokan diawali dengan memilih anakan salak yang berukuran sama dalam setiap ulangan. Selanjutnya bagian pangkal anakan salak dibersihkan dari pelepah-pelepah yang tua. Bagian pangkal anakan salak yang sudah dibersihkan disemprot menggunakan urine sapi sesuai dosis perlakuan sampai basah. Selanjutnya anakan dicangkok menggunakan media tanah yang dimasukkan pada potongan botol plastik.

Tunas cangkokan yang sudah jadi ditransplanting ke polibag dengan media campuran tanah hitam dan pupuk kandang serta diletakkan di tempat yang teduh. Bibit dipupuk dengan 7,5 g NPK/polibag dan disiram selama di pembibitan.

Parameter yang diamati meliputi jumlah daun, tinggi tanaman, jumlah akar primer, panjang akar primer, bobot akar, persentase bibit hidup, serta persentase bibit dengan pucuk daun mengering. Pengamatan dilakukan secara destruktif pada umur 4 bulan setelah proses pencangkokan. Persentase bibit hidup dan bibit dengan pucuk daun mengering diamati 3 minggu setelah cangkokan dipisah dari induknya dan ditransplanting ke polibag.

Data yang diperoleh dianalisis menggunakan analisis ragam pada uji $F 5 \%$. Apabila nilai $F_{\text {hitung }}>$ $F_{\text {tabel, }}$ maka diteruskan dengan uji jarak berganda Duncan (Duncan multiple range test) pada taraf $\alpha=$ 0,05 . 
Tabel 1. Rerata jumlah akar primer, panjang akar primer, bobot akar, jumlah daun, dan tinggi tanaman pada cangkokan yang baru dipanen

\begin{tabular}{cccccc}
\hline $\begin{array}{c}\text { Konsentrasi Urine } \\
(\%)\end{array}$ & $\begin{array}{c}\text { Jumlah akar } \\
\text { primer }\end{array}$ & $\begin{array}{c}\text { Panjang akar primer } \\
(\mathrm{cm})\end{array}$ & Bobot akar $(\mathrm{g})$ & Jumlah daun & $\begin{array}{c}\text { Tinggi } \\
\text { tanaman }(\mathrm{cm})\end{array}$ \\
\hline 0 & $11,67 \mathrm{ab}$ & $30,90 \mathrm{a}$ & $38,00 \mathrm{a}$ & $7,47 \mathrm{a}$ & $193,26 \mathrm{~b}$ \\
10 & $11,00 \mathrm{ab}$ & $22,33 \mathrm{a}$ & $25,67 \mathrm{a}$ & $6,53 \mathrm{a}$ & $188,80 \mathrm{ab}$ \\
20 & $14,67 \mathrm{a}$ & $40,00 \mathrm{a}$ & $55,00 \mathrm{a}$ & $7,20 \mathrm{a}$ & $171,53 \mathrm{a}$ \\
30 & $15,67 \mathrm{a}$ & $29,00 \mathrm{a}$ & $75,00 \mathrm{a}$ & $6,53 \mathrm{a}$ & $199,40 \mathrm{~b}$ \\
40 & $8,67 \mathrm{~b}$ & $27,00 \mathrm{a}$ & $22,00 \mathrm{a}$ & $6,80 \mathrm{a}$ & $199,40 \mathrm{~b}$ \\
\hline KK $(\%)$ & 21,09 & 48,29 & 81,35 & 7,45 & 5,45 \\
\hline
\end{tabular}

Keterangan: $\mathrm{KK}=$ koefisien keragaman; Angka-angka yang diikuti oleh huruf yang sama pada kolom yang sama menunjukkan tidak berbeda nyata menurut uji lanjut DMRT 0,05 .

\section{HASIL DAN PEMBAHASAN}

Analisis statistik memperlihatkan perlakuan urine sapi hanya berpengaruh terhadap jumlah akar primer dan tinggi tanaman (Tabel 1). Rata-rata jumlah akar primer pada cangkokan salak berkisar 8-12 buah. Tunas salak yang disemprot urine 20-30\% mempunyai jumlah akar terbanyak, tetapi berbeda tidak nyata dengan kontrol dan urine $10 \%$. Urine sapi mengandung hormon auksin, giberelin, kinetin yang baik untuk pertumbuhan akar dan tanaman, yang kadarnya beragam sesuai ransum pakannya (Baba, 2013). Tunas salak yang disemprot dengan urine sapi $40 \%$ mempunyai jumlah akar paling sedikit. Hal ini kemungkinan disebabkan penyemprotan dengan konsentrasi yang tinggi akan menyebabkan $\mathrm{pH}$ meningkat, sehingga akan menggangu pertumbuhan tanaman, walaupun pada urine sapi juga terdapat unsur hara seperti N, P, K (Desiana et al., 2013; Dharmayanti et al., 2013; Fitriani dan Salfina, 2016; Suwardi, 2010). Urine sapi mempunyai $\mathrm{pH}$ yang lebih tinggi (pH: 7,3-8,5) dibanding tanah (pH: 6,0) (Desiana et al., 2013; Fitriani dan Salfina, 2016). Semakin berat dan besar perakaran cangkok, maka rasionya terhadap diameter batang dan keliling batang juga tinggi (Prameswari et al., 2014).

Persentase hidup bibit salak dapat ditingkatkan salah satunya melalui peningkatan pertumbuhan akar, yaitu dengan meningkatkan baik jumlah akar maupun bobot akarnya. Dalam kegiatan ini, tunas yang telah dicangkok bisa dipanen/dipisahkan dari induknya setelah tumbuh akar cukup banyak, yaitu sekitar 4 bulan setelah pencangkokan. Pada bagian yang dicangkok jika mendapat aliran zat makanan (karbohidrat) dan auksin (hormon tumbuh yang mendorong keluarnya akar), maka akan terbentuk akar. Aliran nutrisi yang mengalir ke bawah, akan tertahan di bagian atas keratan, sehingga terjadi penimbunan karbohidrat maupun hormon di bagian atas keratan tersebut. Karbohidrat dan hormon yang tertimbun di bagian atas keratan tersebut akan membentuk kalus, selanjutnya tumbuh dan berkembang menjadi akar tanaman. Hasil cangkokan siap dipisah dari induknya jika akar sudah memenuhi media tanam.

Tinggi tanaman dipengaruhi oleh penyemprotan urine sapi. Tunas anakan yang disemprot urine 30-40\% mempunyai tinggi tanaman yang tertinggi, sedangkan tunas anakan yang disemprot urine $20 \%$ mempunyai tinggi tanaman yang terendah, walaupun tidak berbeda nyata dengan urine $10 \%$. Selanjutnya bibit salak sisa pengamatan destruktif ditanam ke polibag untuk diamati persentase tumbuhnya. Pada umur 3 minggu setelah transplanting persentase tumbuh bibit salak antar perlakuan sebesar $100 \%$. Walaupun tanaman masih hidup, tetapi beberapa mengalami mati pucuk/pucuk daun mengering berkisar 8,33-41,67\% (Tabel 2). Pengeringan pucuk daun tersebut kemungkinan disebabkan pupus tergoyang-goyang pada saat proses transplanting, sehingga pertumbuhannya terganggu. Dalam perkembangannya, tanaman yang pucuk daunnya mengering sebagian masih bisa tumbuh kembali. Persentase bibit hidup ini kemungkinan dapat berkurang setelah berumur lebih dari satu bulan.

Tabel 2. Pengaruh urine sapi terhadap persentase hidup cangkokan salak pada umur 3 minggu setelah dipisah dari induknya

\begin{tabular}{ccc}
\hline $\begin{array}{c}\text { Konsentrasi } \\
\text { Urine }(\%)\end{array}$ & $\begin{array}{c}\text { Persentase } \\
\text { bibit hidup } \\
(\%)\end{array}$ & $\begin{array}{c}\text { Persentase bibit yang } \\
\text { pucuk daunnya } \\
\text { mengering }(\%)\end{array}$ \\
\hline 0 & 100 & 25,00 \\
10 & 100 & 25,00 \\
20 & 100 & 8,33 \\
30 & 100 & 41,67 \\
40 & 100 & 41,67 \\
\hline KK $(\%)$ & & 77,01 \\
\hline
\end{tabular}

Keterangan: $\mathrm{KK}=$ Koefisien keragaman.

\section{KESIMPULAN}

Urine sapi bermanfaat untuk memperbanyak jumlah akar. Pemberian urine sapi $20 \%$ dapat meningkatkan jumlah akar primer dan tinggi benih salak. Penggunaan urine sapi dengan konsentrasi yang tepat yakni pada konsentrasi $20 \%$ pada pencangkokan salak dapat meningkatkan keberhasilannya.

\section{UCAPAN TERIMA KASIH}

Penulis mengucapkan terima kasih dan penghargaan yang setinggi-tingginya kepada SMARD yang telah membiayai kegiatan penelitian KP4S ini. 


\section{DAFTAR PUSTAKA}

Baba, B. 2013. Pengaruh pemberian berbagai konsentrasi urine sapi terhadap pertumbuhan bibit stek tanaman kopi Robusta. Agroplantae 2: 23-28.

Desiana, C., I.S. Banuwa, R. Evizal, dan S. Yusnaini. 2013. Pengaruh pupuk organik cair urine sapi dan limbah tahu terhadap pertumbuhan bibit kakao (Theobroma cacao L.). Jurnal Agrotek Tropika 1: 113-119.

Dharmayanti, N.K.S., A.A.N. Supadma, dan I.D.M. Arthagama. 2013. Pengaruh pemberian biourine dan dosis pupuk $(\mathrm{N}, \mathrm{P}, \mathrm{K})$ terhadap beberapa sifat kimia tanah pegok dan hasil tanaman bayam (Amaranthus sp.). Jurnal Agroekoteknologi Tropika 2: 165-174.

Fitriani, M. dan Salfina, N. 2016. Respon tanaman jagung manis (Zea mays Saccharata Sturt) terhadap Pemberian Pupuk Organik Cair Urin Sapi di Kepulauan Riau. Proseding Seminar Nasional "Membangun Pertanian Modern dan Inovatif Berkelanjutan dalam Rangka Mendukung MEA”. 31 Mei- 1 Juni 2016, Jambi. pp: 250-255.

Hadiati, S. 2016. Pengembangan Salak Sari Intan di Bintan. Iptek Hortikultura 12: 81-84.

Kasijadi, F., T. Purbiati, M.C. Mahfudi, dan T. Sudaryono. 1999. Teknologi pembibitan salak secara cangkok. Jurnal Hortikultura 9: 1-7.

Kementerian Pertanian. 2018. Statistik Pertanian 2018. Pusat Data dan Sistem Informasi Pertanian, Kementerian Pertanian Republik Indonesia. $382 \mathrm{p}$.

Kusumo, S., F.A. Bahar, S. Sulihanti, Y. Krisnawati, Suhardjo, dan T. Sudaryono. 1995. Teknologi
Produksi Salak. Pusat Penelitian dan Pengembangan Hortikultura. Jakarta, 62p.

Prameswari, Z.K., S. Trisnowati, dan S. Waluyo. 2014. Pengaruh macam media dan zat pengatur tumbuh terhadap keberhasilan cangkok sawo (Manilkara zapota (L.) van Royen) pada musim penghujan. Vegetalika 3: 107-118.

Purbiati, T., Q.D. Ernawanto, dan S.R. Soemarsono. 1994. Pengaruh komposisi media tumbuh dan ukuran pot terhadap pertumbuhan tunas anakan salak yang diperbanyak secara vegetatif. Penelitian Hortikultura 5: 1-12.

Putri, K.D., Sampoerno, dan F. Puspita. 2016. Pemberian beberapa konsentrasi bio-urin sapi pada bibit tanaman Gaharu (Aquilaria malaccensis). JOM Fakultas Pertanian 3: 1-9.

Priantyo, A. 2002. Urine sapi harapan petani non pestisida. Jurnal Saint dan Teknologi 10: 18-29.

Riski, K., A. Rahayu, dan S.A. Adimihardja. 2016. Pengaruh berbagai konsentrasi IBA dan urine sapi terhadap pertumbuhan stek tanaman lada (Piper nigrum L.). Jurnal Agronida 2: 53-61.

Sudaryono, T., dan M. Soleh. 1994. Induksi akar pada perbanyakan salak secara vegetatif. Penelitian Hortikultura 5: 13-18.

Suwardi. 2010. Efektivitas Pertumbuhan Stek Kopi Robusta dengan Pemberian Zat Perangsang Tumbuh Urine Sapi. Skripsi. Samarinda: Program Studi Budidaya Tanaman Perkebunan. Politeknik Pertanian Negeri Samarinda.

Yunanda, J., Murniati, dan S. Yoseva. 2015. Pertumbuhan stek batang tanaman buah naga (Hylocereus costaricensis) dengan pemberian beberapa konsentrasi urin sapi. JOM Fakultas Pertanian 2: 1-8. 